\title{
BMJ
}

\section{Common mental disorder and obesity-insight from four repeat measures over 19 years: prospective Whitehall II cohort study}

\author{
Mika Kivimäki, professor of social epidemiology, ${ }^{1,2}$ Debbie A Lawlor, professor of epidemiology, ${ }^{3}$ Archana \\ Singh-Manoux, senior research fellow, ${ }^{1,4} \mathrm{G}$ David Batty, Wellcome Trust fellow, ${ }^{5,6,7}$ Jane E Ferrie, senior \\ research fellow, ${ }^{1}$ Martin J Shipley, senior lecturer in medical statistics, ${ }^{1}$ Hermann Nabi, research fellow, ${ }^{4}$ \\ Séverine Sabia, research fellow, ${ }^{4}$ Michael G Marmot, head of department and director, ${ }^{1}$ Markus Jokela, senior \\ research fellow ${ }^{1,2}$
}

'Department of Epidemiology and Public Health, University College London, London WC1E 6BT

${ }^{2}$ Finnish Institute of Occupational Health, Helsinki, Finland

${ }^{3}$ MRC Centre for Causal Analyses in Translational Epidemiology, University of Bristol, Bristol ${ }^{4}$ INSERM U687-IFR69, Hôpital Paul Brousse, Villejuif Cedex, France

${ }^{5}$ MRC Social and Public Health Sciences Unit, University of Glasgow, Glasgow

${ }^{6}$ Centre for Cognitive Ageing and Cognitive Epidemiology, University of Edinburgh, Edinburgh

${ }^{7}$ The George Institute for International Health, University of Sydney, Sydney, Australia

Correspondence to: M Kivimäki m.kivimaki@ucl.ac.uk

Cite this as: BMJ 2009;339:b3765 doi:10.1136/bmj.b3765

\section{ABSTRACT}

Objectives To examine potential reciprocal associations between common mental disorders and obesity, and to assess whether dose-response relations exist.

Design Prospective cohort study with four measures of common mental disorders and obesity over 19 years (Whitehall II study).

Setting Civil service departments in London.

Participants 4363 adults (28\% female, mean age 44 years at baseline).

Main outcome Common mental disorder defined as general health questionnaire "caseness;" overweight and obesity based on Word Health Organization definitions.

Results In models adjusted for age, sex, and body mass index at baseline, odds ratios for obesity at the fourth screening were 1.33 (95\% confidence interval 1.00 to 1.77), 1.64 (1.13 to 2.36), and 2.01 (1.21 to 3.34) for participants with common mental disorder at one, two, or three preceding screenings compared with people free from common mental disorder ( $P$ for trend 0.001 ). The corresponding mean differences in body mass index at the most recent screening were $0.20,0.31$, and 0.50 ( $P$ for trend 0.001 ). These associations remained after adjustment for baseline characteristics related to mental health and exclusion of participants who were obese at baseline. In addition, obesity predicted future risk of common mental disorder, again with evidence of a doseresponse relation ( $P$ for trend $=0.02$, multivariable model). However, this association was lost when people with common mental disorder at baseline were excluded ( $P$ for trend=0.33).

Conclusions These findings suggest that in British adults the direction of association between common mental disorders and obesity is from common mental disorder to increased future risk of obesity. This association is cumulative such that people with chronic or repeat episodes of common mental disorder are particularly at risk of weight gain.

\section{INTRODUCTION}

Common mental disorders, such as depression and anxiety, have been hypothesised to increase the risk of obesity, but the evidence is inconclusive. ${ }^{1}$ Some studies show higher rates of obesity in people with mental health problems, ${ }^{2-5}$ whereas others report no association, ${ }^{6}$ or even a reverse effect, although this last has largely been seen in subgroups that offer limited generalisability. ${ }^{47}$ As the development of obesity has a relatively long induction period, chronic or recurrent mental disorder is a more plausible cause than transient mental disorder. However, previous studies have typically measured common mental disorder at only one time point.

Other series of studies have explored the opposite causal direction - that is, obesity as a risk factor for future mental disorder. Again, the results from these studies have been contradictory. ${ }^{8}$ Some studies find that people with greater body mass index have an increased risk of depression and anxiety disorders, ${ }^{6910}$ others report no association of obesity with these outcomes, ${ }^{11}$ and another group of studies report negative associations (greater obesity being associated with reduced risk of future mental health problems and suicide). ${ }^{12} 13$

Several mechanisms could explain these two causal directions. The associations between obesity and common mental disorder may be context specific, depending on, for example, attitudes towards body size and mental ill health, such that the nature of the associations differs in different populations. That is, in societies in which obesity is stigmatised, this may lead to increased risk of anxiety and depression. ${ }^{14}$ On the other hand, stress and common mental disorders themselves are associated with disordered eating, which could influence future changes in adiposity, ${ }^{15}$ and commonly used treatments for depression have known side effects that also could lead to weight gain. ${ }^{17}$

Given the public health importance of the increasing rates of both obesity and common mental disorder, ${ }^{18} 19$ 
understanding the nature of the association between these two conditions is crucial and could potentially inform prevention and treatment. Prospective studies with repeat measurements of both common mental disorder and obesity offer a unique opportunity for in-depth study of this, but they are rare. Such studies have the capacity to explore the possible reciprocal nature of these associations and determine whether a dose-response (cumulative) effect exists in either direction. This study takes advantage of four waves of medical screening from the Whitehall II study of British government employees to determine the direction and possible dose-response nature of the association between common mental disorder and obesity.

\section{METHODS}

\section{Study population}

The target population of the British Whitehall II study was all London based office staff, aged 35-55, working in 20 civil service (government) departments at study baseline in $1985-8 .{ }^{20} \mathrm{With}$ a response of $73 \%$, the baseline cohort consisted of 10308 employees (6895 men and 3413 women).

\section{Design}

Since the first medical examination (phase 1, 1985-8), follow-up screenings with a medical examination have taken place on three occasions over a 19 year period: phase 3 (1991-3), phase 5 (1997-9), and phase 7 (2003-4). All these phases included a standardised assessment of common mental disorder (general health questionnaire, described below) and direct measurement of weight and height from which body mass index was derived.

\section{Baseline characteristics}

Demographic characteristics, behavioural risk factors, and chronic health conditions measured were age, ethnicity (white $v$ non-white), marital status (married or cohabiting $v$ other), socioeconomic position (high, intermediate, or low, derived from civil service employment grade), smoking (never smoker, exsmoker, 1-10, 11-20, or $>20$ cigarettes a day), alcohol consumption $(0,1-21$, and $>21$ units of alcohol a week for men; 0, 1-14, and >14 units for women), physical activity (vigorous, moderate, or mild), systolic blood pressure ( $\mathrm{mm} \mathrm{Hg}$ ), diastolic blood pressure ( $\mathrm{mm} \mathrm{Hg}$ ), total cholesterol (mmol/l), diabetes (self reported), and coronary heart disease. ${ }^{20}$ Coronary heart disease was defined by using the multinational monitoring of trends and determinants in cardiovascular disease (MONICA) criteria, ${ }^{21}$ using responses to questions about chest pain and diagnoses by physicians, examination of medical records, and electrocardiography findings. We considered these variables as potential confounders or mediating factors in the association between common mental disorder and obesity.

\section{Common mental disorder}

We assessed common mental disorders by using the self administered 30 item general health questionnaire, ${ }^{22}$ a screening instrument designed for community settings. It has been validated against standardised clinical interviews, has shown high reliability, and has been widely used in large population based surveys and trials and shown high predictive validity such that people classified as "cases" have raised mortality relative to non-cases. ${ }^{23}$

Each general health questionnaire item inquires about a specific symptom. Response categories are scored as either 1 or 0 to indicate whether the symptom is present or not. On the basis of receiver operating characteristics and previous studies, we defined people with a total score of 5 or more as general health questionnaire cases and those scoring 0-4 as non-cases. ${ }^{24}$ In this study, in which the scores were validated against a clinical interview schedule, sensitivity $(73 \%)$ and specificity $(78 \%)$ measures indicate that this definition of "caseness" is acceptable. ${ }^{24}$ Given that we explored bidirectional associations between common mental disorders and obesity, caseness (and obesity) could be considered an exposure variable or an outcome.

\section{Obesity and overweight}

We calculated body mass index as weight (kilograms)/ height (metres) squared. Following the World Health Organization's definition, we considered participants with a body mass index of 25-29.9 to be overweight

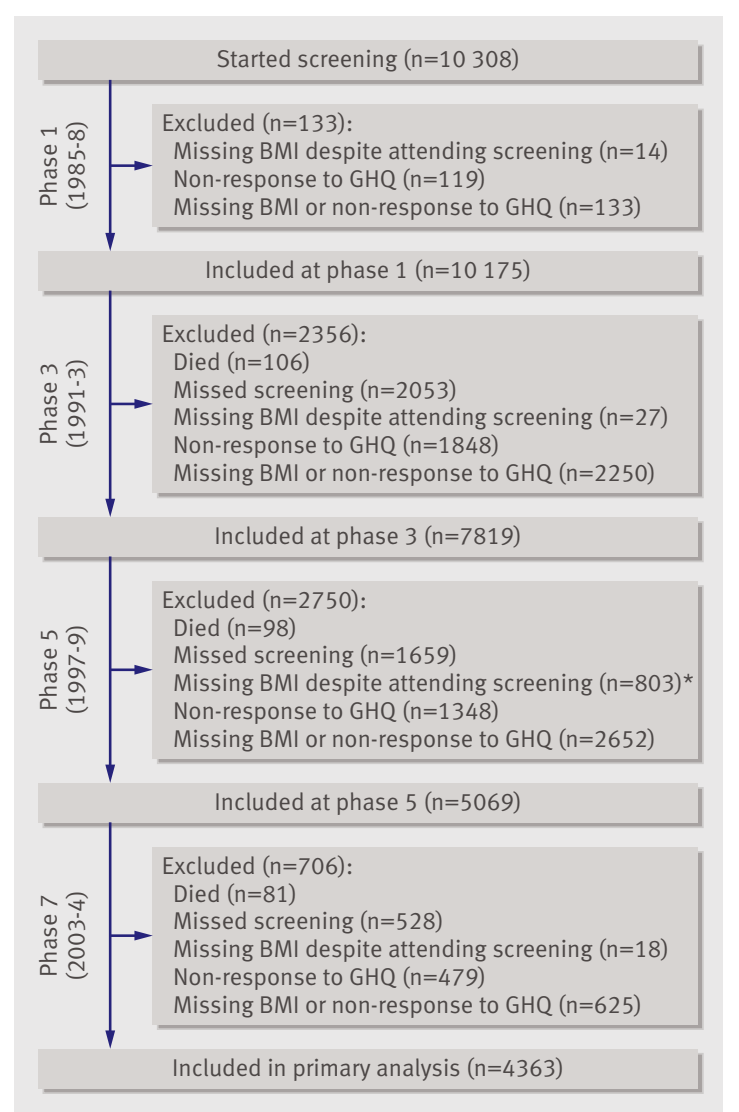

Flow chart of follow-up. BMI=body mass index; $\mathrm{GHQ}=$ =general health questionnaire. * Greater number of participants with missing BMI at this phase is due to sickness among clinic personnel 
Table 1/Comparison of the characteristics of the analytical sample with those of people in the excluded baseline population. Values are numbers (percentages) unless stated otherwise

\begin{tabular}{|c|c|c|c|}
\hline Baseline characteristic & $\begin{array}{l}\text { Included } \\
(n=4363)\end{array}$ & $\begin{array}{l}\text { Excluded* } \\
(n=5412)\end{array}$ & $\begin{array}{c}\mathrm{P} \text { for } \\
\text { heterogeneity }\end{array}$ \\
\hline Mean (SD) age (years) & $44.0(6.0)$ & $44.4(6.1)$ & $<0.001$ \\
\hline \multicolumn{4}{|l|}{ Sex: } \\
\hline Men & $3122(71.6)$ & $3416(63.1)$ & $<0.001$ \\
\hline Women & $1241(28.4)$ & $1996(36.9)$ & \\
\hline \multicolumn{4}{|l|}{ Ethnicity: } \\
\hline White & $4042(92.7)$ & $4691(87.8)$ & $<0.001$ \\
\hline Non-white & $319(7.3)$ & $651(12.2)$ & \\
\hline \multicolumn{4}{|l|}{ Marital status: } \\
\hline Married or co-habiting & $3341(76.8)$ & $3826(72.6)$ & $<0.001$ \\
\hline Single/divorced/widow & $1011(23.2)$ & $1442(27.4)$ & \\
\hline \multicolumn{4}{|l|}{ Socioeconomic position: } \\
\hline High & $1484(34.0)$ & $1380(26.1)$ & $<0.001$ \\
\hline Intermediate & $2256(51.7)$ & $2418(45.7)$ & \\
\hline Low & $620(14.2)$ & $1495(28.2)$ & \\
\hline \multicolumn{4}{|l|}{ Smoking status: } \\
\hline Never smoked & $2303(53.8)$ & $2566(48.6)$ & 0.005 \\
\hline Ex-smoker & $1454(34.0)$ & $1671(31.7)$ & \\
\hline Light smoker (1-10 cigarettes/day) & $198(4.6)$ & $310(5.9)$ & \\
\hline Moderate smoker (11-20 cigarettes/day) & $225(5.3)$ & $475(9.0)$ & \\
\hline Heavy smoker ( $>20$ cigarettes/day) & $102(2.4)$ & $255(4.8)$ & \\
\hline \multicolumn{4}{|l|}{ Alcohol intake: } \\
\hline None & $630(14.5)$ & $1105(20.6)$ & $<0.001$ \\
\hline Moderate (1-20 units/week) & $3118(71.9)$ & $3514(65.6)$ & \\
\hline Heavy ( $\geq 21$ units/week) & $586(13.6)$ & $737(13.8)$ & \\
\hline \multicolumn{4}{|l|}{ Physical exercise: } \\
\hline Mild/none & $1159(26.8)$ & $1747(32.9)$ & $<0.001$ \\
\hline Moderate & $2177(50.4)$ & $2525(47.5)$ & \\
\hline Vigorous & $982(22.7)$ & 1039 (19.6) & \\
\hline Mean (SD) systolic blood pressure (mm Hg) & $122.1(13.9)(n=4359)$ & $123.2(15.0)(n=5402)$ & $<0.001$ \\
\hline Mean (SD) diastolic blood pressure $(\mathrm{mm} \mathrm{Hg})$ & $76.2(9.7)(n=4359)$ & $77.2(10.4)(n=5402)$ & $<0.001$ \\
\hline Mean (SD) total cholesterol (mmol/l) & $5.88(1.11)(n=4339)$ & $5.99(1.20)(n=5366)$ & $<0.001$ \\
\hline \multicolumn{4}{|l|}{ Diabetes: } \\
\hline No & $4318(99.5)$ & $5303(98.9)$ & 0.001 \\
\hline Yes & $22(0.5)$ & $61(1.1)$ & \\
\hline \multicolumn{4}{|l|}{ Coronary heart disease: } \\
\hline No & $4338(99.4)$ & $5351(98.9)$ & $<0.001$ \\
\hline Yes & $25(0.6)$ & $61(1.1)$ & \\
\hline \multicolumn{4}{|l|}{ Use of psychotropic drug: } \\
\hline No & $4239(97.2)$ & $5090(96.2)$ & 0.005 \\
\hline Yes & $121(2.8)$ & $202(3.8)$ & \\
\hline \multicolumn{4}{|l|}{ GHQ caseness: } \\
\hline No & 3199 (73.3) & $3848(72.6)$ & 0.45 \\
\hline Yes & $1164(26.7)$ & $1450(27.4)$ & \\
\hline \multicolumn{4}{|l|}{ BMI category: } \\
\hline Normal weight & $2793(64.0)$ & $3179(58.7)$ & \\
\hline Overweight & $1356(31.1)$ & $1783(32.9)$ & \\
\hline Obese & $214(4.9)$ & $450(8.3)$ & $<0.001$ \\
\hline BMI $\left(\mathrm{kg} / \mathrm{m}^{2}\right)$ & $24.3(3.2)$ & $24.8(3.7)$ & $<0.001$ \\
\hline
\end{tabular}

$\mathrm{BMI}=$ body mass index; $\mathrm{GHQ}=$ general health questionnaire (measure of common mental disorder).

*Not including 533 people who died during follow-up from phase 1 to phase 7.

and those with a body mass index of 30 or above to be obese. ${ }^{25}$ Weight was measured in underwear to the nearest $0.1 \mathrm{~kg}$ on Soehnle electronic scales. Height was measured in bare feet to the nearest $1 \mathrm{~mm}$ by using a stadiometer with the participant standing erect with his or her head in the Frankfort plane. Repeatability of the weight and height measurements over one month (that is, between participant variability/total (between +within participant) variability), done for 306 participants, was 0.99 at the phase 7 screening.

\section{Statistical analysis}

To explore potential selection bias, we first compared baseline characteristics between participants included in the analytical sample and those excluded by using $\chi^{2}$ test (categorical variables) or $t$ test (continuous traits). In the analytical sample, we then ran two sets of analyses to examine the dose-response pattern and direction of the association between common mental disorders and obesity. We used Stata 10.1 statistical software for Windows for all analyses.

Analysis 1: common mental disorder as a risk factor for subsequent overweight and obesity-We divided participants into four groups on the basis of the number of times they were general health questionnaire cases at the first three measurement phases (phases 1, 3, and 5). We used multinomial logistic regression analysis to summarise the association between occurrence of caseness and body mass index category $(<25$ (normal weight), 25-29.9 (overweight), $\geq 30$ (obese)) at the end of follow-up (phase 7). This method enabled us to examine whether the association between caseness and obesity differed from that for overweight. The multinomial regression analysis produced odds ratios for being overweight and obese at the last screening (both compared with a reference of normal weight) for participants who had been general health questionnaire cases no, one, two, or three times at the preceding screenings.

Analysis 2: obesity as a risk factor for future common mental disorder - In these analyses, we divided participants into four groups on the basis of the number of times they were obese at the first three measurement phases (no, one, two, or three times). We examined the associations between occurrence of obesity and general health questionnaire caseness at the end of follow-up (phase 7) by using logistic regression analysis.

In both analysis 1 and 2, we found no evidence of sex or ethnic differences in any of the associations between general health questionnaire caseness and obesity $(\mathrm{P}=0.34-0.98$ for all sex and ethnicity interactions). Therefore, we pooled the data for men and women and for ethnic groups and made appropriate adjustments in subsequent analyses. In both analyses, we estimated regression estimates and accompanying 95\% confidence intervals firstly without adjustments and then with control for age, sex, and baseline body mass index category (analysis 1) or baseline general health questionnaire caseness (analysis 2). Further adjustments took into account all baseline characteristics to examine other potential confounding or mediated effects.

\section{Sensitivity analyses}

To test the robustness of our findings, we ran three types of sensitivity analysis. Firstly, to examine 
Table 2 | Multivariate models of association between occurrence of common mental disorder (GHQ caseness) and subsequent BMI category $(n=4154)$

\begin{tabular}{|c|c|c|c|c|}
\hline \multirow{2}{*}{$\begin{array}{l}\text { No of times GHQ case } \\
\text { at phases } 1,3 \text {, and } 5\end{array}$} & \multirow[b]{2}{*}{ No of participants } & \multirow{2}{*}{$\begin{array}{c}\text { Odds ratio }(95 \% \mathrm{Cl}) \\
\text { for overweight* } \\
v \text { normal weight } \\
\text { at phase } 7 \text { (model } \mathrm{A} \dagger)\end{array}$} & \multicolumn{2}{|c|}{$\begin{array}{c}\text { Odds ratio }(95 \% \mathrm{Cl}) \text { for obese* } \\
v \text { normal weight at phase } 7\end{array}$} \\
\hline & & & Model A† & Model B $\ddagger$ \\
\hline 0 & 2259 & 1.00 (reference) & 1.00 (reference) & 1.00 (reference) \\
\hline 1 & 1111 & $1.19(0.99$ to 1.41$)$ & 1.33 (1.00 to 1.77$)$ & 1.31 (0.98 to 1.76$)$ \\
\hline 2 & 555 & 1.32 (1.05 to 1.66$)$ & 1.64 (1.13 to 2.36$)$ & 1.63 (1.12 to 2.37$)$ \\
\hline 3 & 229 & $1.00(0.71$ to 1.40$)$ & 2.01 (1.21 to 3.34$)$ & 2.01 (1.19 to 3.39) \\
\hline Test for trend & & $P=0.07$ & $P<0.001$ & $P<0.001$ \\
\hline
\end{tabular}

$\mathrm{BMI}=$ body mass index; $\mathrm{GHQ}=$ general health questionnaire (measure of common mental disorder).

*1518 (36.5\%) normal weight; 1938 (46.7\%) overweight; 698 (16.8\%) obese.

†Adjusted for age, sex, and BMI category at phase 1.

¥As model A, but additionally adjusted for ethnicity, marital status, socioeconomic position, smoking, alcohol intake, physical activity, systolic blood pressure, diastolic blood pressure, total cholesterol, diabetes, coronary heart disease, and use of psychotropic drugs at phase 1.

temporality in the associations, we focused on subgroups, excluding from the analyses people who were obese or overweight at baseline (analysis 1) and people who were general health questionnaire cases at baseline (analysis 2). Secondly, to examine whether the association between caseness and subsequent obesity was sensitive to the predefined body mass index cut-off points used, we repeated analysis 1 using linear regression analysis with continuous body mass index (rather than the category) as the outcome. Thirdly, to further explore the impact of selection bias resulting from missing data, we used multiple multivariate imputation and repeated the analyses on the basis of an imputed sample of all participants who were alive during the whole study period ( $\mathrm{n}=9775)$ (see web appendix)

\section{RESULTS}

Sample selection and sample characteristics

The figure shows the selection of the sample. Of the 10308 participants at phase $1,10175(98.7 \%)$ had complete data on weight, height, and general health questionnaire caseness. At the following phase, these data were available for 7819 participants $(77.7 \%$ of the phase 1 participants who had complete data at phase 1 and were alive at phase 3). At phases 5 and 7, the corresponding figures were $5069(65.7 \%$ of those alive at phase 5$)$ and $4363(87.5 \%$ of those alive at phase 7). Our main analysis was based on those 4363 participants (3122 men and 1241 women) who had complete data on common mental disorders, weight, and height at baseline and all follow-up measurements (44.6\% of the baseline cohort after exclusion of the 533 participants who died during follow-up).

The mean age of the included participants with complete data was 44.0 years, and $26.7 \%$ met the criteria for general health questionnaire caseness at phase 1 (table 1). A comparison of people included in the analyses with those excluded because of loss to follow-up or missing data revealed modest differences, although statistical significance was often reached because of the large numbers. Participants included were 0.4 years younger, were less often obese, and had a 0.5 lower body mass index and a somewhat more favourable risk factor profile than did excluded participants. We found no differences in the prevalence of general health questionnaire caseness between the two groups, although the proportion of people on psychotropic drug treatment was $1.0 \%$ lower among the participants than among the people excluded.

Analysis 1: common mental disorder as a risk factor for subsequent overweight and obesity

The mean follow-up from phase 1 to phase 7 was 16.5 (range 14.6-18.8) years, and the mean observation period over the first three screenings was 11.0 (9.1-13.3) years. Of the participants included in the analysis, 2379 $(54.5 \%)$ never met the definition for general health questionnaire caseness across the first three screenings, $1159(26.6 \%)$ were cases at one screening, $585(13.4 \%)$ were cases at two screenings, and $240(5.5 \%)$ were cases at all three screenings.

Occurrence of general health questionnaire caseness was associated with subsequent obesity (compared with being of normal weight) in a dose-response manner: unadjusted odds ratios were 1.11 (95\% confidence interval 0.90 to 1.36 ), 1.27 (0.98 to 1.66 ), and 1.56 (1.10 to 2.21) for caseness at one, two, and three screenings compared with participants who were case-free $(\mathrm{P}$ for trend $=0.004)$. We found no robust association between general health questionnaire caseness at the first three screenings and subsequent overweight in the unadjusted analysis ( $\mathrm{P}$ for trend $=0.83$, data not shown). Table 2 shows multivariate models for these associations among the 4154 participants with complete data. The dose-response association with obesity was robust to adjustment for a wide range of potential covariates: age, sex, and baseline body mass index category (model A); plus ethnicity, marital status, socioeconomic position, smoking, alcohol intake, physical activity, blood pressure, total cholesterol, diabetes, coronary heart disease, and use of psychotropic drugs (model B).

\section{Analysis 2: obesity as a risk factor for future common mental disorder}

Of the 4363 participants, 3727 (85.4\%) were not obese at any of the three phases; $291(6.7 \%)$ were obese once, $175(4.0 \%)$ were obese twice, and $170(3.9 \%)$ were obese on three occasions. The odds ratios of general health questionnaire caseness at phase 7 increased with the number of times participants were obese. Compared with non-obese people, the odds ratios in unadjusted analysis for those who were obese one, two, or three times were 1.29 (0.97 to 1.71), 1.35 (0.95 to 1.93 ), and 1.45 (1.02 to 2.06) (P for trend=0.004). However, as shown in multivariate models (table 3 ), all the odds ratios between obesity categories and subsequent general health questionnaire caseness were nonsignificant when adjusted for covariables, although the overall trend remained $(\mathrm{P}$ for trend $=0.01$ in model A and 0.02 in model B).

\section{Sensitivity analyses}

We repeated analyses 1 and 2 in subgroups to further study the temporal order between general health 
Table 3 |Multivariate models of association between obesity and subsequent common mental disorder (GHQ caseness; $n=4154$ )

\begin{tabular}{|c|c|c|c|}
\hline \multirow{2}{*}{$\begin{array}{l}\text { No of times obese at phases } \\
1,3 \text {, and } 5\end{array}$} & \multirow{2}{*}{$\begin{array}{c}\text { No of } \\
\text { participants }\end{array}$} & \multicolumn{2}{|c|}{ Odds ratio $(95 \% \mathrm{Cl})$ for $\mathrm{GHQ}$ caseness* at phase 7} \\
\hline & & Model A† & Model B $\ddagger$ \\
\hline 0 & 3557 & 1.00 (reference) & 1.00 (reference) \\
\hline 1 & 272 & 1.21 (0.89 to 1.62$)$ & 1.21 (0.89 to 1.63$)$ \\
\hline 2 & 166 & 1.35 (0.93 to 1.97$)$ & 1.36 (0.93 to 1.99$)$ \\
\hline 3 & 156 & 1.43 (0.98 to 2.10$)$ & 1.39 (0.94 to 2.05$)$ \\
\hline Test for trend & & $P=0.01$ & $P=0.02$ \\
\hline
\end{tabular}

$\mathrm{GHQ}=$ general health questionnaire (measure of common mental disorder).

*834 (20.1\%) were GHQ cases at phase 7.

†Adjusted for age, sex, and GHQ caseness at phase 1.

$\ddagger$ As model A, but additionally adjusted for ethnicity, marital status, socioeconomic position, smoking, alcohol

intake, physical activity, systolic blood pressure, diastolic blood pressure, total cholesterol, diabetes, coronary heart disease, and use of psychotropic drugs at phase 1.

questionnaire caseness and obesity (table 4). The doseresponse relation between occurrence of caseness and subsequent obesity remained after exclusion of participants who were obese at phase $1(\mathrm{n}=214, \mathrm{P}$ for trend $<0.001)$ and those who were overweight $(\mathrm{n}=1356, \mathrm{P}$ for trend $=0.03)$. By contrast, in the analysis to test the reverse direction, the association between occurrence of obesity and subsequent general health questionnaire caseness was lost when participants defined as cases at phase $1(\mathrm{n}=1164)$ were excluded from the analysis ( $\mathrm{P}$ for trend $=0.33$ ).

Further testing dealt with the association between general health questionnaire caseness and subsequent obesity. Results from the analysis with continuous body mass index at phase 7 as the outcome were consistent with the main findings using categories of body mass index. In models adjusted for age, sex, and body mass index at baseline, mean differences in body mass index at the fourth study phase were $0.20(95 \%$ confidence interval 0.02 to 0.37$), 0.31$ (0.09 to 0.54 ), and $0.50(0.17$ to 0.83$)$ for people defined as general health questionnaire cases one, two, or three times relative to those who were never defined as cases $(\mathrm{P}$ for trend $<0.001, \mathrm{n}=4154)$. After adjustment for all baseline covariates and exclusion of obese participants at phase 1 , the corresponding mean differences were 0.19 (0.03 to 0.35$), 0.38$ (0.16 to 0.59$)$, and 0.40 (0.09 to 0.72 ), again clearly supporting a dose-response association ( $\mathrm{P}$ for trend $<0.001, \mathrm{n}=3957$ ).

We used multiple imputation to repeat the analyses reported in table 2 (common mental disorder as a predictor of obesity) on the basis of all participants alive at phase 7, a total of 9775 people (see web appendix). The dose-response association between general health questionnaire caseness and subsequent obesity was very similar to that obtained in the complete case analysis (table 2). Occurrence of caseness was also associated with subsequent overweight $(\mathrm{P}$ for trend $=0.02$ ) in these analyses.

\section{DISCUSSION}

Findings from this well characterised occupational cohort of more than 4000 men and women provide evidence that common mental disorder may be a risk factor for future obesity. Additionally, we found evidence that this effect seems to be cumulative. Thus, the odds ratio of being obese at the fourth and final screening were two times higher for participants with common mental disorder at all three preceding screenings than for those who were disorder-free at all previous screenings. Evidence existed of a doseresponse effect in the association of common mental disorder with obesity, such that people who had more episodes of the disorder had a greater risk of obesity. This dose-response association was independent of a wide range of mental health related characteristics at baseline that may be associated with both obesity and common mental disorder, including initial body mass index, age, sex, ethnicity, marital status, socioeconomic position, smoking, alcohol intake, physical activity, blood pressure, cholesterol, diabetes, coronary heart disease, and use of psychotropic drugs. We saw a similar pattern of associations when we used body mass index as a continuous variable.

When we examined the association in the opposite direction (that is, obesity as a risk factor for common mental disorder), we also found a dose-response association. However, when we removed participants with common mental disorder at baseline no association of obesity with future risk of common mental disorder existed. These results suggest a temporal sequence from mental disorder to obesity in this cohort of British adults.

\section{Strengths and weaknesses}

Randomised controlled trials are important for showing causal effects, but in this case, where the interest is in the association between long term mental disorder and obesity, they may not be feasible. In such cases, observational data provide the best available source of evidence, although they can never provide complete proof of causality. For example, even though adjustment for a wide range of covariates had little effect on our estimates of association, the possibility of residual confounding cannot be excluded in observational research.

Despite a high response to the survey (range 66-88\%) at the successive data collection phases, loss to followup accumulated over the extended time period, as is inevitable in all long term prospective studies. However, associations were similar in our complete case analyses and analyses based on multivariate multiple imputation datasets (web appendix). Multivariate multiple imputation, in common with other procedures for dealing with missing data, assumes similarity in the associations between the exposure and outcome in participants with and without missing data. This assumption cannot be tested in any real dataset, but among those with missing data, "missingness" would have to be more common for people with both mental disorder and low body mass index or with both an absence of mental disorder and high body mass index to create a spurious association between common mental disorder and obesity. We cannot see any reason why this should be the case. 
Table 4 | Subgroup analyses testing temporal order between GHQ caseness and obesity

\begin{tabular}{|c|c|c|}
\hline Subcohort at phase 1 and exposure & No of participants & Odds ratio $(95 \% \mathrm{Cl})$ \\
\hline \multicolumn{3}{|l|}{ Non-obese participants $(n=4149)$} \\
\hline $\begin{array}{l}\text { No of times } G H Q \text { case at phases } 1,3 \text {, and } \\
\text { 5: }\end{array}$ & & Outcome: obese $v$ normal weight at phase $7^{*}$ \\
\hline 0 & 2274 & 1.00 (reference) \\
\hline 1 & 1101 & $1.43(1.03$ to 1.99$)$ \\
\hline 2 & 550 & 1.81 (1.19 to 2.75$)$ \\
\hline 3 & 224 & 2.61 (1.45 to 4.69$)$ \\
\hline Test for trend & & $P<0.001$ \\
\hline
\end{tabular}

Normal weight participants $(\mathrm{n}=2793)$

No of times GHQ case at phases 1, 3, and 5

\begin{tabular}{lcc}
\hline 0 & 1487 & 1.00 (reference) \\
\hline 1 & 762 & $1.39(0.75$ to 2.57$)$ \\
\hline 3 & 388 & $2.05(1.05$ to 4.02$)$ \\
\hline est for trend & 156 & $1.89(0.71$ to 5.06$)$ \\
\hline
\end{tabular}

Participants not GHQ cases $(n=3199)$

No of times obese at phases 1,3 , and 5 :

\begin{tabular}{lcc}
\hline 0 & 2746 & 1.00 (reference) \\
\hline 1 & 203 & $1.13(0.77$ to 1.66$)$ \\
\hline 3 & 126 & $1.17(0.72$ to 1.88$)$ \\
\hline
\end{tabular}

Test for trend $\mathrm{P}=0.33$

$\mathrm{GHQ}=$ general health questionnaire (measure of common mental disorder).

*Adjusted for age, sex, and body mass index at baseline.

†Adjusted for age and sex. extended follow-up period. These analyses therefore make a unique contribution to this area of research. Our findings are in agreement with a recent longitudinal study of elderly people that showed weight gain to be more common among people with symptoms of depression than among those who were symptomfree. ${ }^{5}$ Our results are also consistent with those from another cohort that used two sets of measurements to explore the bidirectional association between depression and type 2 diabetes, a condition associated with raised body mass index. ${ }^{10}$ In that study, baseline depressive symptoms were associated with increased risk of type 2 diabetes at the second follow-up (two years later), after removal of people with diabetes at baseline and adjustment for a wide range of potential confounding factors. Given that obesity is the major risk factor for type 2 diabetes, this association would be anticipated from our results, although the association in that study persisted even after adjustment for body mass index, suggesting that it may not be entirely mediated through adiposity. Furthermore, in that cohort, study members with treated type 2 diabetes at baseline were at increased risk of depressive symptoms two years later, again after removal of those with depressive symptoms at baseline and adjustment for a wide range of potential confounding factors, including body mass index. ${ }^{10}$ Interestingly, impaired fasting glucose and untreated diabetes at baseline were not associated with risk of depressive symptoms two years later, raising the possibility that the association of treated diabetes with future symptoms may be related to diagnosis of a chronic disease (or the treatment in terms of drugs and dietary restrictions) rather than to obesity or other specific biological mechanisms underlying diabetes. This possibility is consistent with our findings suggesting no real association between obesity and subsequent common mental disorder. mental health rather than diagnosed mental illnesses. ${ }^{2627}$ In order to characterise long term mental health problems, we calculated the number of times that each participant met the criteria for common mental disorder over the first three phases of the study. In doing so, we gave equal weight to data from each phase as the purpose was to estimate each participant's propensity for common mental disorder over the whole period rather than to estimate proximal or distal effects of disorder on obesity.

Two thirds of our cohort were male white collar workers, potentially reducing the generalisability of our findings. Furthermore, occupational groups are, by their very nature, healthier than their general population, so the range of scores on the general health questionnaire test and the range of body mass index measurements might be narrower. This being the case, the associations reported here will, if anything, be an underestimate of the associations in the general population, which includes people not in employment.

\section{Comparison with previous studies}

We are not aware of any other study that has four repeat measurements of common mental disorders and direct assessment of weight and height over an

\section{Meaning of the study}

The two sets of analyses provide evidence that common mental disorder is predictive of subsequent weight gain and obesity in this population of British middle aged adults. Evidence of a dose-response relation also suggests that people with chronic or repeated episodes of common mental disorder are particularly at risk of subsequent obesity. By contrast, our findings do not suggest that obesity leads to common mental disorders in this population, as the association between the two was attenuated when study members who were general health questionnaire cases at baseline were removed from the analysis.

Several plausible explanations exist for the observation that persistent common mental disorder is a risk factor for obesity. Firstly, common mental disorders are associated with eating disorders, both over-consumption and under-consumption, which could influence future changes in adiposity. ${ }^{1516}$ Secondly, physical inactivity, a major contributing factor to obesity, is more prevalent among people with mental health problems, and some randomised controlled trials suggest that exercise reduces depressive 


\section{WHAT IS ALREADY KNOWN ON THIS TOPIC}

Whether common mental disorders predict obesity or whether obesity predicts common mental disorders is unclear

Few studies have the repeat measures necessary to understand the nature of the association

\section{WHAT THIS STUDY ADDS}

Common mental disorder predicted subsequent obesity in a cohort of 4000 men and women over a 19 year follow-up period

Weight gain and the risk of obesity increased in a dose-response fashion with the number of episodes of common mental disorder

Little evidence existed to suggest that obesity was a risk factor for subsequent common mental disorder in people with no pre-existing mental disorder

symptoms among people with a diagnosis of depression, although in high quality trials the effect is close to the null. ${ }^{28}$ Thirdly, commonly used drug treatments for mental disorders have known side effects that may result in weight gain (tricyclic antidepressants), weight loss (selective serotonin reuptake inhibitors), or both (short term and long term effects of selective serotonin reuptake inhibitors). ${ }^{1729}$ Fourthly, biological factors, such as dysregulation of the hypothalamic-pituitaryadrenocortical axis, may strengthen the link between mental disorders and obesity. ${ }^{30}$ For example, some evidence exists of abnormal concentrations of hormones of the hypothalamic-pituitary-adrenocortical axis among obese people with coexisting depressive symptoms. $^{31}$ All these mechanisms are likely to increase the risk of obesity in a dose-response fashion such that single episodes of, for example, hormonal dysregulation would be less likely to increase risk than would two, three, or more repeated episodes or than would a continuous chronic disorder.

\section{Unanswered questions}

Further longitudinal research is now needed to confirm the generalisability of these findings to wider populations; to identify major social, behavioural, and biological mechanisms underlying the observed associations; to identify the time lag between exposure and outcome; and to determine whether our findings are directly transferable to patients who meet the Diagnostic and Statistical Manual of Mental Disorders or international classification of diseases criteria for specific mental disorders, such as depression. Long term follow-up of randomised controlled trials for the prevention of common mental disorder in vulnerable groups that look at obesity as an outcome would be helpful in proving causality, as would mendelian randomisation studies showing that genetic variants robustly associated with common mental disorder are also related to obesity. If the observed associations are causal, our findings have important implications for prevention and treatment. As obesity is a major risk factor for various chronic conditions and premature death, ${ }^{19}$ an increased risk of obesity induced by mental health problems should be taken into account in the treatment of persistent common mental disorders.
We thank all participating civil service departments and their welfare personnel and establishment officers; the Occupational Health and Safety Agency; the Council of Civil Service Unions; all participating civil servants in the Whitehall II study; and all members of the Whitehall II Study Team. The Whitehall II Study Team comprises research scientists, statisticians, study coordinators, nurses, data managers, administrative assistants, and data entry staff, who make the study possible.

Contributors: All authors jointly designed the hypothesis, analysed and interpreted the data, and wrote the paper. MK is guarantor.

Funding: The Whitehall II study has been supported by grants from the Medical Research Council; British Heart Foundation; Health and Safety Executive; Department of Health; National Heart Lung and Blood Institute US, NIH (R01HL036310-20A2); National Institute on Aging, US, NIH (R01AG034454-01 and R01AG013196); Agency for Health Care Policy Research; and the John D and Catherine T MacArthur Foundation Research Networks on Successful Midlife Development and Socioeconomic Status and Health. MK is supported by the Academy of Finland; GDB is a Wellcome Trust research fellow; AS-M is supported by a "EURYI" award from the European Science Foundation; JEF is supported by the Medical Research Council; MJS is supported by the British Heart Foundation; and MGM is supported by an MRC research professorship. The funders did not contribute to the study design and had no role in data collection, data analysis, data interpretation, or writing of the report. The researchers were independent from the funders.

Competing interests: None declared

Ethical approval: The University College London Medical School committee on the ethics of human research gave ethical approval for the Whitehall II study.

1 McElroy SL, Kotwal R, Malhotra S, Nelson EB, Keck PE, Nemeroff CB. Are mood disorders and obesity related? A review for the mental health professional. J Clin Psychiatry 2004;65:634-51, quiz 730.

2 Goodman E, Whitaker RC. A prospective study of the role of depression in the development and persistence of adolescent obesity. Pediatrics 2002;110:497-504.

3 Weil E, Wachterman M, McCarthy EP, Davis RB, O’Day B, lezzoni LI, et al. Obesity among adults with disabling conditions. JAMA 2002;288:1265-8.

4 Stunkard AJ, Faith MS, Allison KC. Depression and obesity. Biol Psychiatry 2003;54:330-7.

5 Vogelzangs N, Kritchevsky SB, Beekman AT, Newman AB, Satterfield S, Simonsick EM, et al. Depressive symptoms and change in abdominal obesity in older persons. Arch Gen Psychiatry 2008;65:1386-93.

6 Roberts RE, Deleger S, Strawbridge WJ, Kaplan GA. Prospective association between obesity and depression: evidence from the Alameda County Study. Int J Obes Relat Metab Disord 2003;27:514-21.

7 Heo M, Pietrobelli A, Fontaine KR, Sirey JA, Faith MS. Depressive mood and obesity in US adults: comparison and moderation by sex, age, and race. Int J Obes (Lond) 2006;30:513-9.

8 Atlantis E, Baker M. Obesity effects on depression: systematic review of epidemiological studies. Int J Obes (Lond) 2008;32:881-91.

9 Farmer A, Korszun A, Owen MJ, Craddock N, Jones L, Jones I, et al. Medical disorders in people with recurrent depression. $\mathrm{Br} J$ Psychiatry 2008;192:351-5.

10 Golden SH, Lazo M, Carnethon M, Bertoni AG, Schreiner PJ, Roux AV, et al. Examining a bidirectional association between depressive symptoms and diabetes. JAMA 2008;299:2751-9.

11 Istvan J, Zavela K, Weidner G. Body weight and psychological distress in NHANES I. Int J Obes Relat Metab Disord 1992;16:999-1003.

12 Crisp AH, McGuiness B. Jolly fat: relation between obesity and psychoneurosis in general population. BMJ 1976;1:7-9.

13 Magnusson PK, Rasmussen F, Lawlor DA, Tynelius P, Gunnell D. Association of body mass index with suicide mortality: a prospective cohort study of more than one million men. Am J Epidemiol 2006;163:1-8

14 Andreyeva T, Puhl RM, Brownell KD. Changes in perceived weight discrimination among Americans, 1995-1996 through 2004-2006. Obesity (Silver Spring) 2008;16:1129-34.

15 Pallister E, Waller G. Anxiety in the eating disorders: understanding the overlap. Clin Psychol Rev 2008;28:366-86.

16 Dallman MF, Pecoraro N, Akana SF, La Fleur SE, Gomez F, Houshyar H, et al. Chronic stress and obesity: a new view of "comfort food". Proc Natl Acad Sci U S A 2003;100:11696-701.

17 Sussman N, Ginsberg DL, Bikoff J. Effects of nefazodone on body weight: a pooled analysis of selective serotonin reuptake inhibitor and imipramine-controlled trials. / Clin Psychiatry 2001;62:256-60.

18 Compton WM, Conway KP, Stinson FS, Grant BF. Changes in the prevalence of major depression and comorbid substance use 
disorders in the United States between 1991-1992 and 2001-2002. Am J Psychiatry 2006;163:2141-7.

19 Kopelman PG. Obesity as a medical problem. Nature 2000;404:635-43.

20 Marmot MG, Davey Smith G, Stansfeld S, Patel C, North F, Head J, et al. Health inequalities among British civil servants: the Whitehall I study. Lancet 1991;337:1387-93.

21 Tunstall-Pedoe H, Kuulasmaa K, Amouyel P, Arveiler D, Rajakangas AM, Pajak A. Myocardial infarction and coronary deaths in the World Health Organization MONICA project: registration procedures, event rates, and case-fatality rates in 38 populations from 21 countries in four continents. Circulation 1994;90:583-612.

22 Goldberg DP. Detecting psychiatric illness by questionnaire. Oxford University Press, 1972.

23 Huppert FA, Whittington JE. Symptoms of psychological distress predict 7-year mortality. Psychol Med 1995;25:1073-86.

24 Stansfeld SA, Marmot MG. Social class and minor psychiatric disorder in British civil servants: a validated screening survey using the general health questionnaire. Psychol Med 1992;22:739-49.
25 World Health Organization. Physical status: the use and interpretation of anthropometry: report of a WHO expert committee. WHO, 1995. (WHO Technical Report Series.)

26 Prince M, Patel V, Saxena S, Maj M, Maselko J, Phillips MR, et al. No health without mental health. Lancet 2007;370:859-77.

27 World Health Organization. International statistical classification of diseases and related health problems, 9th version. WHO, 1997.

28 Mead GE, Morley W, Campbell P, Greig CA, McMurdo M, Lawlor DA. Exercise for depression. Cochrane Database Syst Rev 2008(4):CD004366.

29 Demyttenaere K, Jaspers L. Review: bupropion and SSRI-induced side effects. J Psychopharmacol 2008;22:792-804.

30 Bornstein SR, Schuppenies A, Wong ML, Licinio J. Approaching the shared biology of obesity and depression: the stress axis as the locus of gene-environment interactions. Mol Psychiatry 2006;11:892-902

31 Gluck ME, Geliebter A, Hung J, Yahav E. Cortisol, hunger, and desire to binge eat following a cold stress test in obese women with binge eating disorder. Psychosom Med 2004;66:876-81.

Accepted: 7 July 2009 